\title{
New Processes to Extract Pure Betacarotenes Molecules Using Acetic Acid Solvent
}

\author{
Andry Tahina Rabeharitsara, Phandry Nomena Ndjiva Rabearimihaja \\ Department Chemical Engineering of E.S.P.A, Antananarivo University, Antananarivo, Madagascar
}

Email address:

rabeharitsara_andrytahina@yahoo.fr (A. T. Rabeharitsara), phandryrandjiva@gmail.com (P. N. N. Rabearimihaja)

To cite this article:

Andry Tahina Rabeharitsara, Phandry Nomena Ndjiva Rabearimihaja. New Processes to Extract Pure Betacarotenes Molecules Using Acetic Acid Solvent. American Journal of Applied Chemistry. Vol. 4, No. 2, 2016, pp. 64-70. doi: 10.11648/j.ajac.20160402.15

Received: February 23, 2016; Accepted: March 10, 2016; Published: March 28, 2016

\begin{abstract}
Betacarotenes molecules extractions using acetic acid (99\% of purity) as solvent followed by distillated water neutralization or hexane solvent to get back betacarotenes. To obtain pure betacarotenes molecules, distillation step is necessary for the second process which use hexane solvent; however for the first process which use distillated water neutralization, decantation step is enough. The first process is energetically profitable. Unrefined palm oil which contains betacarotenes molecules with triglycerides and grease acids is used as model product for betacarotenes extraction. Both of the two processes have extraction rate more than $27 \%$ which increases proportionally with the weight of unrefined palm oil used for extraction.
\end{abstract}

Keywords: Extraction, Betacarotenes, Acetic Acid, Hydrogen Bond, Process, Neutralization, Decantation

\section{Introduction}

Betacarotenes molecules have been widely used in food and pharmaceutical industries. They were seen in many natural products such as: palm grains, carrots, tomatoes, spinach, etc.... [1]. Betacarotenes molecules have been obtained by chemical synthesis or by extraction. This paper show two news processes to extract betacarotenes molecules. The main of these processes is the first step which use acetic acid 99\% purity like solvent extraction. Then, the first process use distillated water to obtain pure betacarotenes molecules after decantation whereas solvent hexane is used for the second process and distillation is necessary to separate pure betacarotenes molecules. The first process is energetically profitable than the second process which need energy to evaporate the solvent "hexane" under vacuum for getting back the pure betacarotenes molecules. Unrefined palm oil which contains betacarotenes molecules with triglycerides and grease acids is used as model product for betacarotenes extraction. Both of the two processes have extraction rate of pure betacarotenes more than $27 \%$ which increases proportionally with the weight of unrefined palm oil used for extraction.

\section{Acetic Acid Extraction Followed by Water Neutralization}

\subsection{Principle of the Process Betacarotenes Extraction with Acetic Acid Followed by Water Neutralization}

It was shown that hydrogen bond link [2] exist between betacarotenes molecules and animal's grease or betacarotenes molecules and vegetable's grease. The hydrogen bond is an attractive interaction between a hydrogen atom from a molecule or a molecular fragment $\mathrm{X}-\mathrm{H}$ in which $\mathrm{X}$ is more electronegative than $\mathrm{H}$, and an atom or a group of atoms in the same or a different molecule, in which there is evidence of bond formation. A typical hydrogen bond may be depicted as $\mathrm{X}-\mathrm{H} \ldots \mathrm{Y}-\mathrm{Z}$, where the three dots denote the bond. $\mathrm{X}-\mathrm{H}$ represents the hydrogen bond donor. The acceptor may be an atom or an anion $\mathrm{Y}$, or a fragment or a molecule $\mathrm{Y}-\mathrm{Z}$, where $\mathrm{Y}$ is bonded to $\mathrm{Z}$. In some cases, $\mathrm{X}$ and $\mathrm{Y}$ are the same. In more specific cases, $\mathrm{X}$ and $\mathrm{Y}$ are the same and $\mathrm{X}-\mathrm{H}$ and $\mathrm{Y}-\mathrm{H}$ distances are the same as well leading to symmetric hydrogen bonds. In any event, the acceptor is an electron rich region such as, but not limited to, a lone pair of $Y$ or $\pi$-bonded pair of Y-Z. [3]. That is why carotenoids are soluble in animal's grease and vegetable's grease [4]. During their transfers 
between the various levels of the trophic networks, the carotenoid pigments are not appeared as isolated molecules: they are often related to other molecules which allow their integration in the cellular structures of the living matter, and thus they are met integrated in lipoproteins, caroténoprotéines or caroténolipoprotéines. They play also a part in the pigmentation, coloring, but also in the reproduction and seem to be at the origin of the visual pigments [5]. Unrefined Palm oil contents are betacarotenes, grease acids and Triglycerides. That is why the color of the unrefined palm oil "Fig. 1".

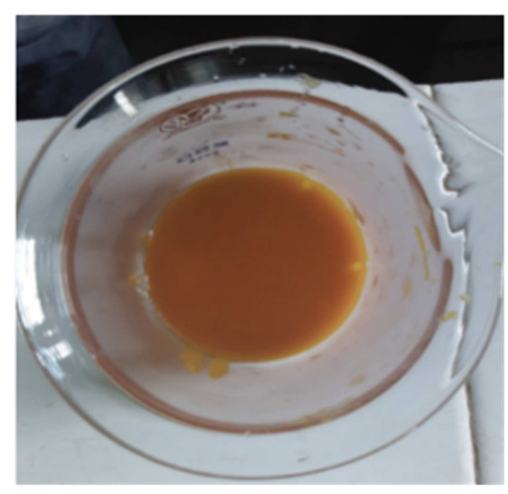

Figure 1. Photo of unrefined palm oil.

The goal of this extraction process is to break the hydrogen bond links between betacarotenes molecules and triglycerides or grease molecules by acetic acids molecules. At the end, betacarotenes molecules will be on hydrogen bond link with acetic acids molecules. Next, distilled water is added progressively. Betacarotenes molecules, which are insoluble in water, became on top up to gather. Underneath, there is acid acetic solution which are up to gather because of hydrogen bond link: cycle dimer of acetic acid [6-7], the molecules form pairs (dimers), being connected by hydrogen bonds. The dimers can also be detected in the vapor at $120^{\circ} \mathrm{C}$ $\left(248^{\circ} \mathrm{F}\right)$ [8]. Dimers also occur in the liquid phase in dilute solutions in non-hydrogen-bonding solvents [8], and a certain extent in pure acetic acid but are disrupted by hydrogenbonding solvents. The dissociation enthalpy of the dimer is estimated at $65.0-66.0 \mathrm{~kJ} / \mathrm{mole}$, and the dissociation entropy at $154-157 \mathrm{~J} \mathrm{~mol}^{-1} \mathrm{~K}^{-1}$ [8]. Other lower carboxylic acids dimerize in a similar fashion [9].

\subsection{Details of the Process Betacarotenes Extraction with Acetic Acid Followed by Water Neutralization}

\subsubsection{Step 1 Reagents Preparation}

Unrefined palm oil is weighed then put in the beaker. Next, acetic acid $99 \%$ of purity is added "Fig. 7". Its $\mathrm{pH}$ is equivalent to $\mathrm{pH}=3.27$. The majority of the acetic acid molecules $(\mathrm{pKa}=4.76)$ are on not dissociated $(\mathrm{R}-\mathrm{COOH})$ acid form "Fig. 2" [10-11-12-13-14-15-16].
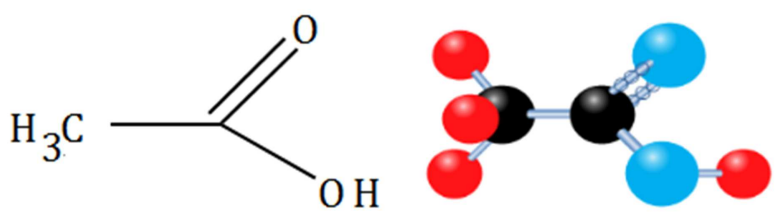

Figure 2. Figure of acetic acid molecule not dissociated.

\subsubsection{Step 2 Mixing Reactants}

Unrefined palm oil and acetic acid are mixed for few minutes "Fig. 7". Hydrogen bond links between triglycerides molecules or grease acids molecules and betacarotenes molecules are broken "Fig. 3" by the acetic acid solvent. From this moment, steric attraction begin between acetic acid molecules and betacarotenes molecules and supports their hydrogen bond links. Steric attraction occurs when molecules have shapes or geometries that are optimized for interaction with one another. In these cases molecules will react with each other most often in specific arrangements [17].

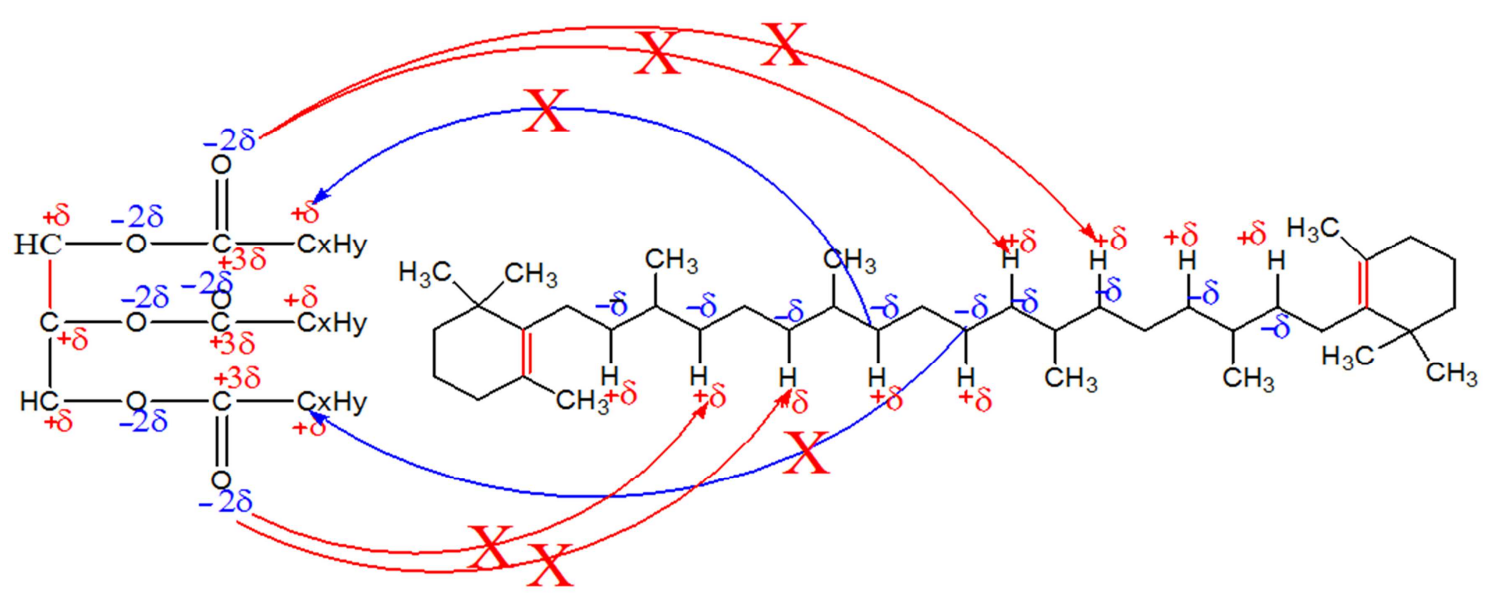

Figure 3. Figure of the broken hydrogen bond links between triglyceride molecule and betacarotenes molecules.

\subsubsection{Step 3 Formation of Hydrogen Bond Links Between Betacarotenes Molecules and Acetic Acids Molecules}

Transvase the mixed solution in the funnel, and let it rest during thirty minutes "Fig. 7". Hydrogen bond links between acetic acid molecules and betacarotenes molecules have taken seat "Fig. 4". 


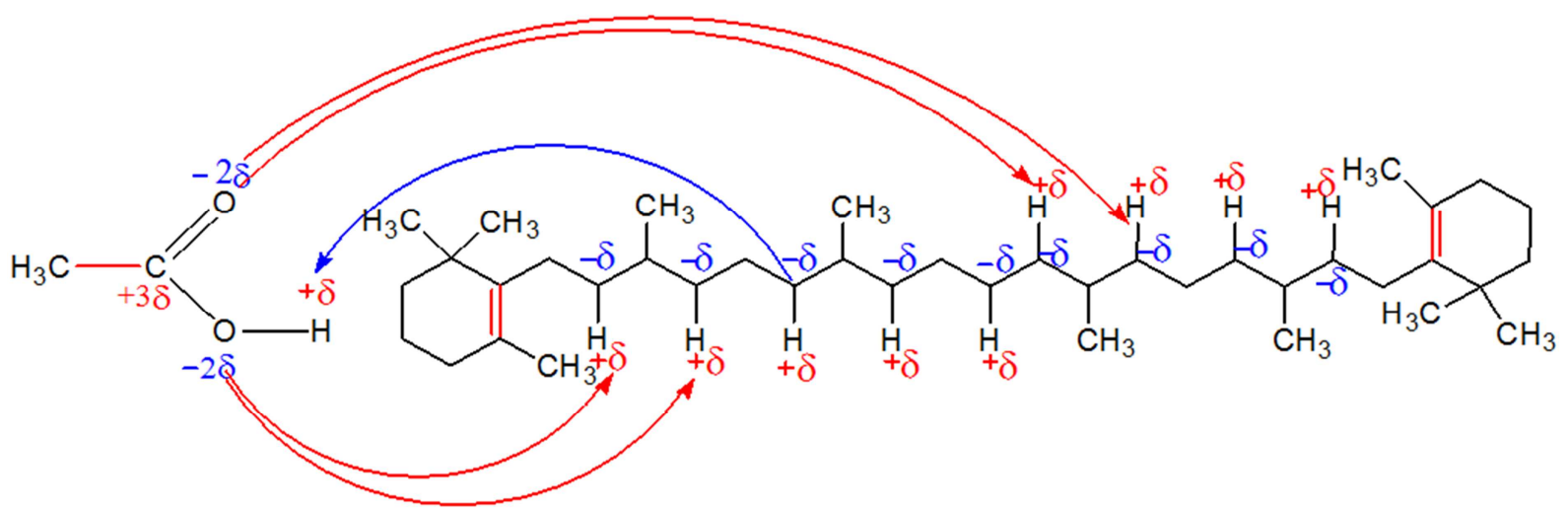

Figure 4. Figure of the formation of hydrogen bond links between acid acetics molecule and betacarotenes molecules.

Two phases are observed. Betacarotenes molecules with acetic acid are underneath and on top there were triglycerides molecules and grease acids molecules "Fig. 5". Next, we take off the underneath phase which was rich on betacarotenes. To improve the betacarotenes extraction, we have added acetic acid in the rest of on top phase which became rich on triglycerides and grease acids molecules, then we take off the underneath phase. We repeat this action twice and get back together the acetic acid-betacarotenes solution. Liquid acetic acid is a hydrophilic (polar) protic solvent, similar to ethanol and water.

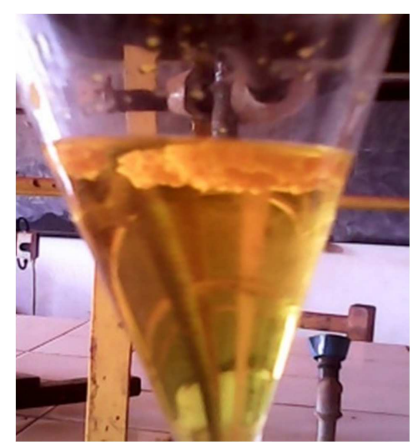

Figure 5. Figure of the two phases after few minutes putting back: betacarotenes molecules with acetic acid underneath and triglyceridesgrease acids molecules on top to gather.

With a moderate relative static permittivity (dielectric constant) of 6.2, it dissolves not only polar compounds such as inorganic salts and sugars, but also non-polar compounds such as oils and elements such as sulfur and iodine. It readily mixes with other polar and non-polar solvents such as water, chloroform, and hexane. With higher alkanes (starting with octane), acetic acid is not completely miscible anymore, and its miscibility continues to decline with longer n-alkanes [18]. This dissolving property and miscibility of acetic acid makes it a widely used industrial chemical, for example, as a solvent in the production of dimethyl terephthalate [19].

\subsubsection{Step 4 Water Neutralization of the up to Gather Phase Rich on Betacarotenes}

Distillated water is added progressively in the up to gather phase rich on betacarotenes which are soluble in acetic acids 99\% "Fig. 7". The water play the basic role $\left(\mathrm{H}_{2} \mathrm{O} / \mathrm{H}_{3} \mathrm{O}^{+}\right)$[2021]. In the same time, the acetic acids-betacarotenes solution will be diluted in water and the $\mathrm{pH}$ of the solution increase progressively to seven. This is the neutralization step by distillated water. The acetic acid $(\mathrm{pKa}=4.76)$ [22] will be dissociated $[\mathrm{R}-\mathrm{COO}-/ \mathrm{H}+]$ and soluble in water because hydrogen bond links between betacarotenes molecules and acetic acid molecules was broken "Fig. 6-a". Betacarotenes molecules which are insoluble in water became on top to gather. At last, we get back the betacarotenes "Fig. 6-b" by decantation process "Fig. 7".

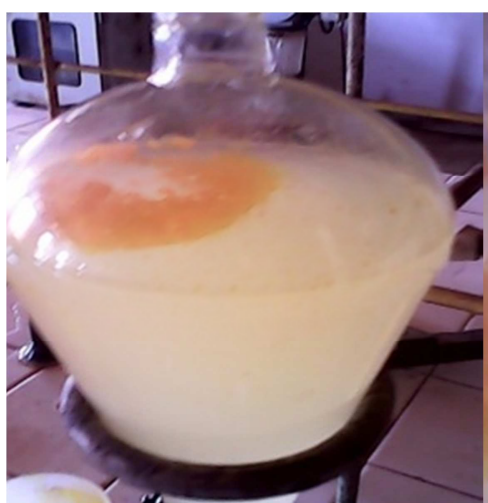

(a)

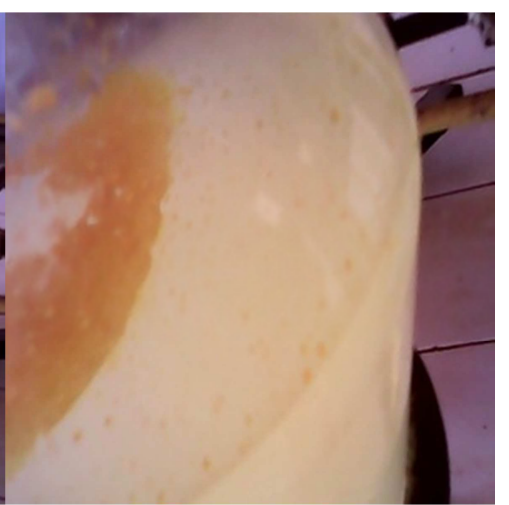

(b)

Figure 6. Figures of the water neutralization step. 


\subsection{Flow-Sheet of the Process Betacarotenes Extraction with Acetic Acid Followed by Water Neutralization}

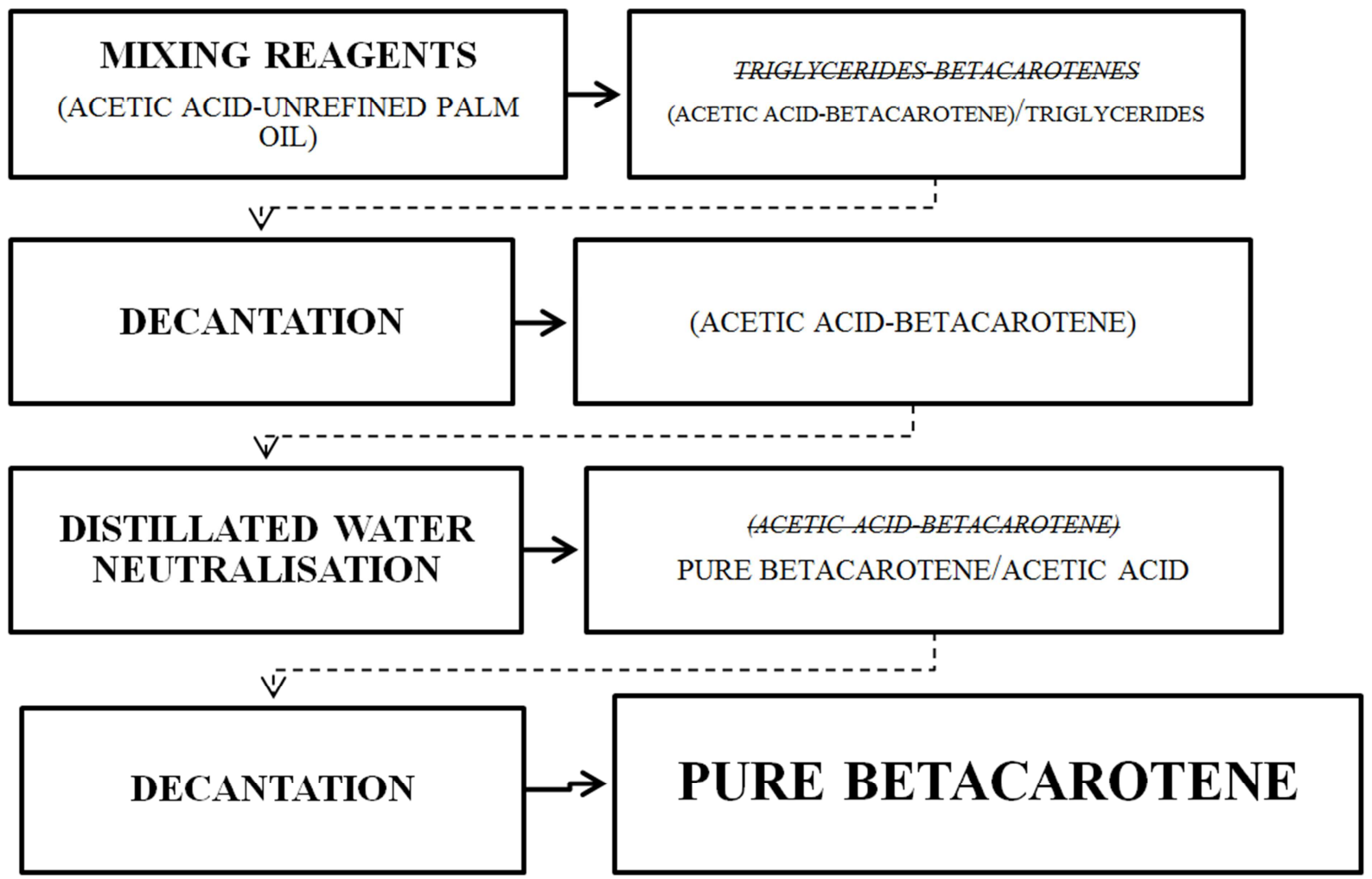

Figure 7. Flow-sheet of the process betacarotenes extraction with acetic acid followed by water neutralization.

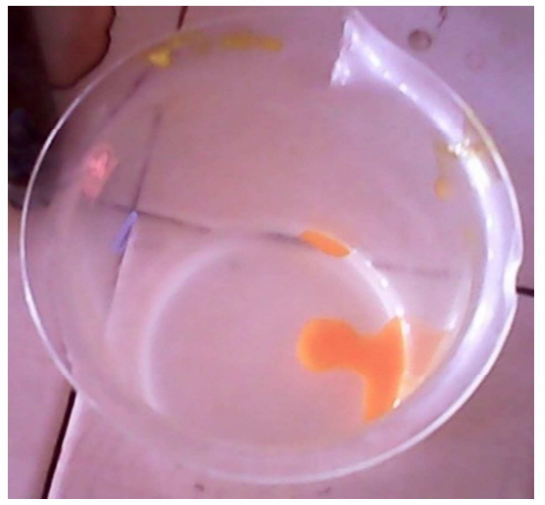

(a)

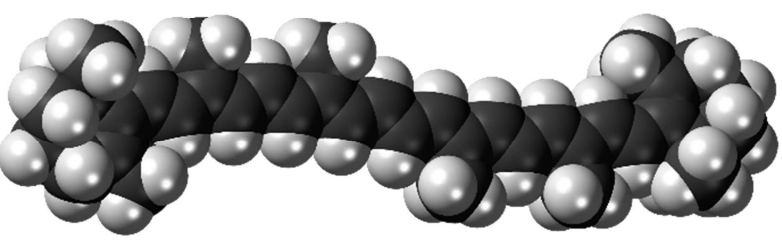

(b)

Figure 8. Figures of pure betacarotenes extracted. [23]

The $\beta$-Carotene extracted is a strongly colored red-orange "Fig. 8-a". It is a pigment abundant in plants and fruits. Betacarotene is a well-known antioxidant [24]. Eating a diet rich in them is often recommended. Benefits from taking supplements are not supported [25-26]. It is an organic compound and chemically is classified as a hydrocarbon and specifically as a terpenoid (isoprenoid). The structure was deduced by Karrer et al. in 1930 with eleven double combined connections [27] "Fig. 8-b". The chemical formula of betacarotenes is $\mathrm{C}_{40} \mathrm{H}_{56}$. It is insoluble in water with 1.05 [g.ml ${ }^{-1}$ ] density. Its molar mass is equal to 536.8726 [g. mol ${ }^{-1}$ ]. And its boiling point is $654.7\left[{ }^{\circ} \mathrm{C}\right]$ at $760[\mathrm{mmHg}]$. Betacarotenes are soluble in hexane solvent.

The experimental results of beta-carotene solubilities in binary mixed solvents formed by cyclohexane, n-hexane, 1hexene and toluene with 2,5,8-trioxanonane, acetone, and cyclohexanone are reported. The solubility of beta-carotene in pure solvents increases in the order: 2,5,8-trioxanonane $<$ acetone $<$ n-hexane $<1$-hexene $<$ cyclohexanone $<$ cyclohexane $<$ toluene. In the mixed solvents studied a maximum of beta-carotene solubility is observed, except for the mixed solvents containing toluene. The reported solubility data for binary solvents were smoothed by means of Myers and Scott rational type equation. These results together with our previous results for hydrocarbon polar non-associating component are interpreted in terms of various models of mixtures. For this purpose models based on the Flory and Huggins non-athermal mixture theory, such 
as Acree and Rytting (AR), and the authors (TT) model, are tested. Both models predict qualitatively size and shape of the beta-carotene solubility curves, including the maximum solubility and asymmetry, in contrary to UNIFAC model. The analysis of the TT and AR models indicate an important role of value and asymmetry of the excess Gibbs energy of the mixtures of solvents as a source-increased solubility. The difference between the solubility of beta-carotene in pure solvents and value of the excess Gibbs energy are responsible for the appearance, position and shift of the maximum solubility [28].

\section{Acetic Acid Extraction Followed by Hexane Separation}

\subsection{Principle of the Process Betacarotenes Extraction with Acetic Acid Followed by Hexane Separation}

The principle and steps of this second process are the same than the first process as far as step3 "Fig. 7" - "Fig. 9". The difference is on step4, to break the hydrogen bonds links between betacarotenes molecules and acetic acid molecules, we use hexane solvent. Betacarotenes are soluble in hexane "Fig. 9". We have transvased the solution in the funnel. Let it rest for thirty minutes. There were two phases, the underneath solution was acetic acids and on top there were betacarotenes molecules soluble in hexane (dhexane $=0.655$ g.cm-3) "Fig. 9". To separate these two phases we use decantation for thirty minutes and take off the acetic acid "Fig. 9". Then, to get back the betacarotenes, we have done first distillation of the hexane on rotavapor (TebHexane $=68.73^{\circ} \mathrm{C}$ ) "Fig. 9". The evaporator consists of a heating bath with a rotating flask, in which the liquid is distributed as a thin film over the hot wall surfaces and can evaporate easily [29].

\subsection{Flow-Sheet of the Process Betacarotenes Extraction with Acetic Acid Followed by Hexane Separation}

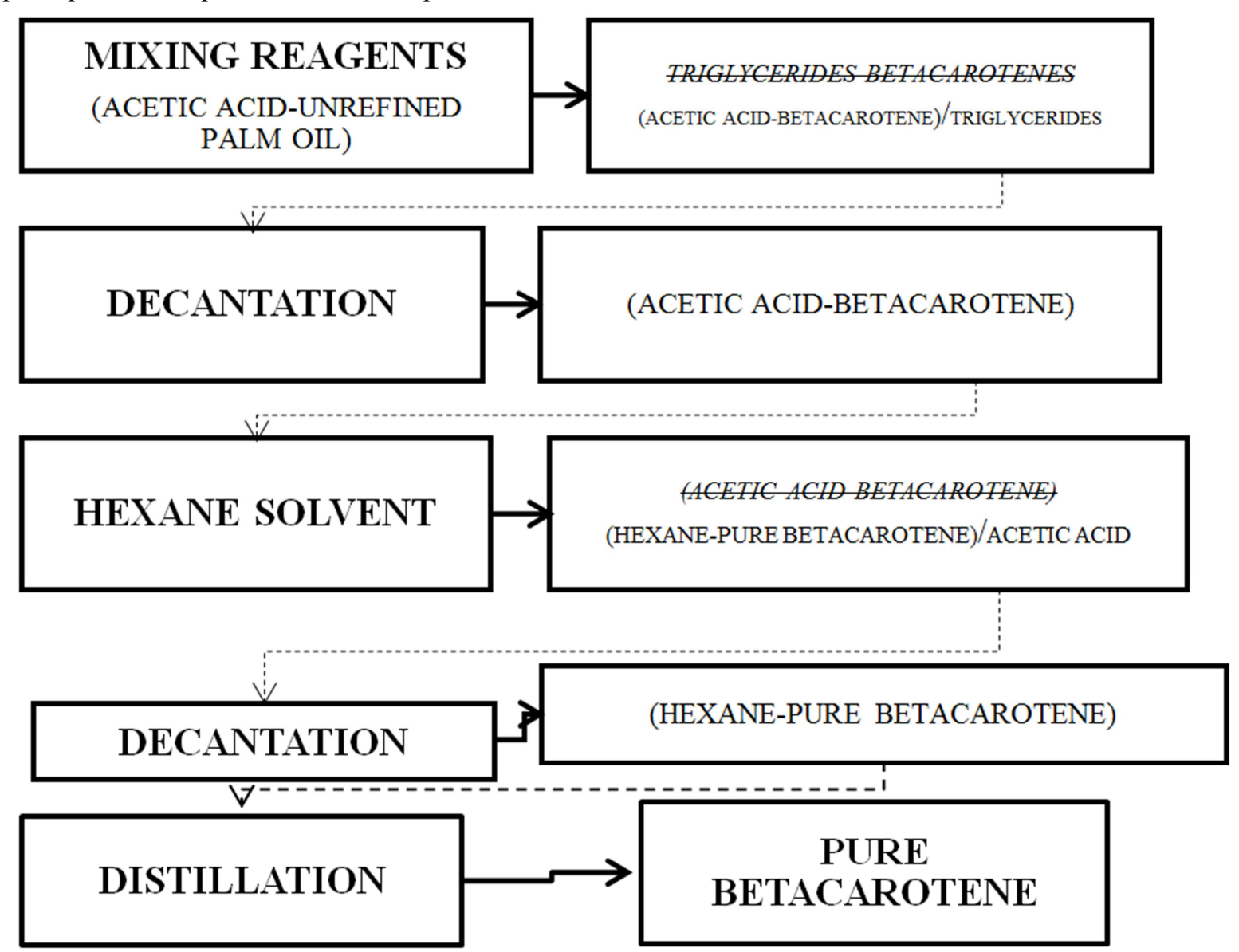

Figure 9. Flow-sheet of the process betacarotenes extraction with acetic acid followed by hexane separation.

\section{Comparisons Between the Two Processes}

The weight of betacarotenes extracted change proportionally with the weight of unrefined oil used for extraction "Fig. 10 - Table 1". In this way we can assert that with both processes we have extracted pure betacarotenes molecules "Fig. 8". The extraction yield is between $27 \%$ and $38 \%$. In other words, the betacarotenes content in $5[\mathrm{~g}]$ of the unrefined palm oil for example is 1.365 [g], either $27.3 \%$. It increase proportionally with the weight of unrefined palm oil used for extraction. 
Table 1. Comparison of extraction yield between the two processes.

\begin{tabular}{lll}
\hline $\begin{array}{l}\text { Unrefined palm } \\
\text { oil quantity } \\
\text { used for } \\
\text { extracting }[\mathbf{g}]\end{array}$ & $\begin{array}{l}\text { Betacarotenes quantity } \\
\text { extracted by the first } \\
\text { process using acetic } \\
\text { acid followed by water } \\
\text { neutralization }[\mathbf{g}]\end{array}$ & $\begin{array}{l}\text { Betacarotenes quantity } \\
\text { extracted by the second } \\
\text { process using acetic acid } \\
\text { followed by hexane } \\
\text { separation }[\mathbf{g}]\end{array}$ \\
\hline 5 & 1.365 & 1.449 \\
10 & 3.150 & 3.192 \\
20 & 6.825 & 7.560 \\
\hline
\end{tabular}

As we see in figure 11 the extractions yield of the first process and second process are equally good. However, the second process seems all the same good when the unrefined oil quantity used for extraction increases. In any case using the first process is energetically profitable. It doesn't use any energy source during the process. However, the second process uses energies during the last stage of distillation which makes it possible to separate the pure molecules of betacarotenes from the solvent hexane [30].
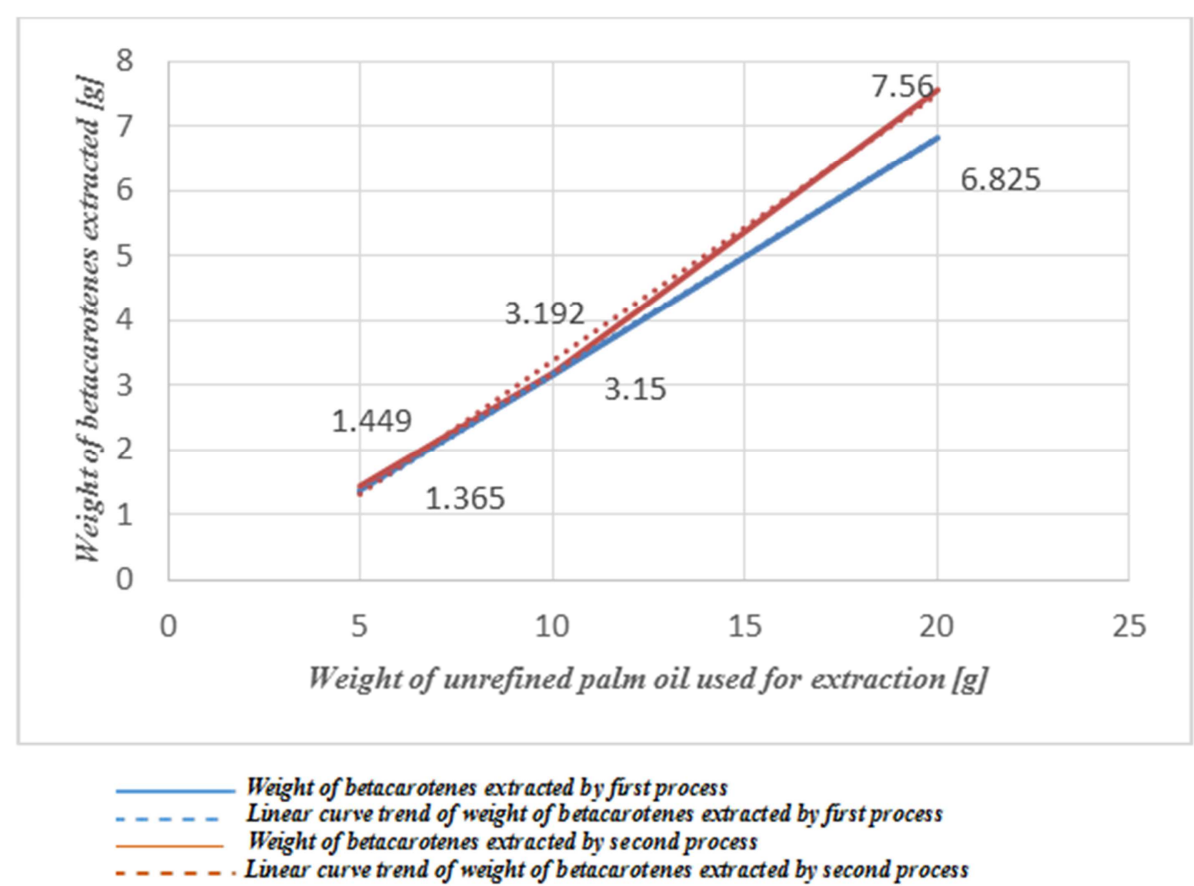

Figure 10. Weight of pure betacarotenes extracted according to the weight of unrefined palm oil used for extraction.

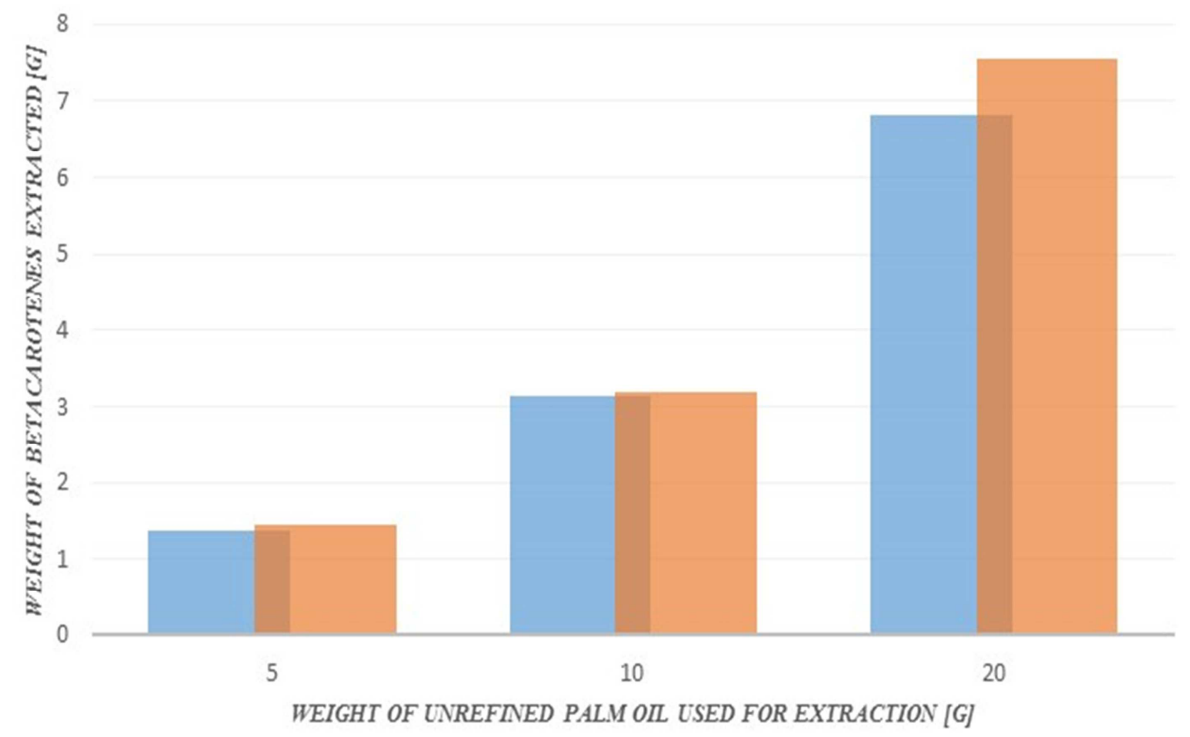

Figure 11. Comparison of betacarotenes quantity extracted by the first process (blue) and the second process (brown).

\section{Acknowledgements}

Special Thanks to everyone who have supported and helped us to carry out this paper. As well, we express our sincere thanks to Director of E.S.P.A Polytechnics of the Antananarivo University and Chemical Engineering Laboratory staff. Special thanks to the company Savonnerie Tropically for giving us unrefined palm oil used during the experiences. 


\section{References}

[1] "USDA National Nutrient Database for Standard Reference, Release 21". Retrieved 2009-07-24.

[2] M. LAFFITTE, F. ROUQUEROL La réaction chimique Tome 1. Aspects structuraux et thermodynamiques, 1991, Eds. Masson p. 9.

[3] E. Arunan, G. R. Desiraju, R. A. Klein, J. Sadlej, S. Scheiner, I. Alkorta, D. C. Clary, R. H., Crabtree, J. J. Dannenberg, P. Hobza, H. G. Kjaergaard, A. C. Legon, B. Mennucci, D. J. Nesbitt. Pure Appl. Chem. 83, 1619 (2011).

[4] B. PAVlOV, A. TERENTIEV Chimie organique Third Edition, 1977, Eds Mir p. 527.

[5] Michel VINCENT, Laboratoire de biochimie et Ecologie des Invertébrés Marins, Ecole Pratique des Hautes Etudes, Centre D'Océanologie de Marseille, UA CNRS 41, Station marine d'Endoume, 13007 Marseille, France, «Rôles et transformations des pigments caroténoides dans les réseaux trophiques marins».

[6] Jones, R.E.; Templeton, D.H. (1958). "The crystal structure of acetic acid". Acta Crystallographica 11 (7): 484-487.

[7] Briggs, James M.; Toan B. Nguyen; William L. Jorgensen (1991). "Monte Carlo simulations of liquid acetic acid and methyl acetate with the OPLS potential functions". Journal of Physical Chemistry 95 (8): 3315-3322.

[8] Togeas, James B. (2005). "Acetic Acid Vapor: 2. A Statistical Mechanical Critique of Vapor Density Experiments". Journal of Physical Chemistry A 109 (24): 5438-5444.

[9] McMurry, John (2000). Organic Chemistry (5 ed.). Brooks/Cole. p. 818.

[10] M. LAFFITTE, F. ROUQUEROL La réaction chimique Tome 2. Aspects thermodynamiques (suites) et cinétiques, 1991, Eds. Masson pp. 28-29.

[11] Perrin, D. D., Dissociation Constants of Organic Bases in Aqueous Solution, Butterworths, London, 1965; Supplement, 1972.

[12] Serjeant, E. P., and Dempsey, B., Ionization Constants of Organic Acids in Aqueous Solution, Pergamon, Oxford, 1979.

[13] Albert, A., "Ionization Constants of Heterocyclic Substances", in Physical Methods in Heterocyclic Chemistry, Katritzky, A. R., Ed., Academic Press, New York, 1963.

[14] Sober, H. A., Ed., CRC Handbook of Biochemistry, CRC Press, Cleveland, Ohio, 1968.

[15] Perrin, D. D., Dempsey, B., and Serjeant, E. P., pK ${ }_{a}$ Prediction for Organic Acids and Bases, Chapman \& Hall, London, 1981.

[16] Dawson, R. M. C., Elliot, D. C., Elliot, W. H., and Jones, K.
M., Data for Biochemical Research, Oxford Science Publications, Oxford, 1986.

[17] Steric Attraction: The Far Side, Ronald R. Sauers Rutgers, State University, New Brunswick, NJ 08903, J. Chem. Educ., 1996, 73 (2), p 114.

[18] Fiume, M. Z.; Cosmetic Ingredients Review Expert Panel (June 2003). "Final report on the safety assessment of triacetin". International Journal of Toxicology 22 (Suppl 2): 1-10.

[19] Hosea Cheung; Robin S. Tanke; G. Paul Torrence (2005), "Acetic Acid", Ullmann's Encyclopedia of Industrial Chemistry, Weinheim: Wiley-VCH.

[20] Paul. ARNAUD, Cours de chimie physique, 14rd éd., Eds. Dunod 1990, pp. 387-388.

[21] Stephen K. Lower, Acid-base equilibria and calculations, December 26, 1996, lower@sfu.ca.

[22] M. LAFFITTE, F. ROUQUEROL La réaction chimique Tome 2. Aspects thermodynamiques (suites) et cinétiques, 1991, Eds. Masson p. 20.

[23] Beta carotene molecule photo www.wikipedia.com

[24] Stargrove, Mitchell (2007-12-20)., Herb, nutrient, and drug interactions: clinical implications and therapeutic strategies (1 ed.). Mosby.

[25] Druesne-Pecollo, N; Latino-Martel, P; Norat, T; Barrandon, E; Bertrais, S; Galan, P; Hercberg, S (Jul 1, 2010). "Betacarotene supplementation and cancer risk: a systematic review and metaanalysis of randomized controlled trials.". International Journal of Cancer. Journal International Du Cancer 127 (1): 172-84.

[26] Mathew MC, Ervin AM, Tao J, Davis RM; Ervin; Tao; Davis (2012). "Routine Antioxidant vitamin supplementation for preventing and slowing the progression of age-related cataract". Cochrane Database Syst Rev 6: CD004567.

[27] P. Karrer, A. Helfenstein, H. Wehrli, A. Wettstein; Helfenstein; Wehrli; Wettstein (1930). "Pflanzenfarbstoffe XXV. Über die Konstitution des Lycopins und Carotins". Helvetica Chimica Acta 13 (5): 1084-1099.

[28] T. Treszczanowicz C,S and A.J. Treszczanowicz, Department of Supramolecular Chemistry, Institute of Physical Chemistry, Polish Academy of Sciences, Warsaw, Poland TTreszcz@ichf.edu.pl, T. Kasprzycka-Guttman Chemistry Department, Warsaw University, Warsaw, Poland, Solubility of Beta-Carotene in Binary Mixed Solvents.

[29] Rosemary Hoegger BÜCHI Labortechnik AG (1998) English, Version B (16 pages) "Distillation with a Rotary Evaporator" Order $\mathrm{N}^{\circ} 97743$.

[30] M. Barthel. Calcul des chaleurs de distillation. J. Phys. Radium, 1930, 1 (12), pp.411-415. 